\title{
Comportamento e afetividade nas redes sociais online
}

\author{
Behavior and affectivity in online social networks
}

\section{Sandra Bordini Mazzocato}

Resumo: Este artigo dispõe sobre trocas em redes sociais online que são motivadas por relações de afetividade. Considera-se este um assunto relevante levando em conta o alto número de usuários que interagem nestes espaços virtuais no Brasil e no mundo. Procura-se para este fim traçar um breve panorama quanto a comportamentos recentes que vêm ganhando força e visibilidade inseridos neste processo, como criação de perfis no Instagram e uso de aplicativos de namoro. Traça-se também um comparativo entre os comportamentos mais atuais com os que já existiam no início da popularização da internet, bem como seus primeiros usos para trocas sociais. Propõe-se que as tecnologias não são causadoras absolutas dos fenômenos sociais, mas sim que a própria sociedade e suas demandas levam à criação destas ferramentas, que em contrapartida, potencializam e dão mais visibilidade a estes comportamentos e trocas afetivas. Concluise que, ao invés de criar proibições ou moderações legais aos meios tecnológicos, deve-se proporcionar informações aos indivíduos para que estes saibam avaliar qual o melhor uso que podem dar para seus perfis em redes sociais.

Palavras-chave: Comportamento; Afetividade; Redes sociais on-line.
Abstract: This article addresses the personal exchanges in online social networks that are motivated by affectionate relationships. This is considered a relevant issue due to the high number of users who interact in these virtual spaces in Brazil and worldwide. To this end, it is intended to provide a brief overview of recent behaviors that have been gaining strength and visibility as part of this process, such as the creating of Instagram profiles and the use of dating applications. A comparison is also made between the most current behaviors with those that already existed at the beginning of the popularization of the Internet, and its first uses for social exchanges. It is proposed that technologies are not absolute causes of this social phenomenon, but that society itself and its demands lead to the creation of these tools, which potentiate and give more visibility to these behaviors and affective exchanges. It is concluded that instead of creating legal prohibitions or moderations to technological means, information should be provided to individuals so that they can evaluate the best use for their social networking profiles by themselves.

Keywords: Behavior; Affectivity; Online social networks. 
0 presente artigo propõe-se a discorrer sobre as mudanças de comportamento da sociedade dos últimos anos ocasionadas pelas inovações em tecnologias digitais. Atualmente, com a democratização do acesso à banda larga e aos dispositivos móveis, ocorre um aumento da participação dos sujeitos em ambientes de redes sociais. 0 Facebook é a plataforma que domina o mercado, atingindo 127 milhões de usuários², somente no Brasil em julho de 2018. Já o Instagram é o campeão de engajamento, possuindo no mundo 1 bilhão ${ }^{3}$ de usuários ativos por dia, sendo 0 Brasil o segundo colocado no ranking de interações.

As evidências não ficam apenas nos números e preenchem o cotidiano da maioria dos brasileiros com exemplos empíricos. Cada vez mais é possível observar pessoas com dificuldade de se separarem de seus aparelhos celulares. Os conteúdos gerados e engajamento criado pelas pessoas permeiam diversas esferas de suas vidas, desde o profissional até momentos íntimos e pessoais.

Seja para postar uma foto ou um vídeo, mandar uma mensagem, curtir ou comentar, é comum ver as pessoas utilizando seus celulares em espaços públicos e privados para acessarem suas redes sociais. São variados os motivos que levam as pessoas a esta prática, desde uma simples busca de algo que ocupe um espaço de tédio, até um alívio para um momento de ansiedade. 0 fato é que os indivíduos entram nestes espaços com frequência, gerando conteúdo e dados relativos aos seus interesses pessoais.

A partir destes números e exemplos citados coloca-se o seguinte questionamento: 0 que motiva as pessoas a interagirem nas redes sociais online? E quais os principais comportamentos que surgem diante desta prática?

\section{Internet e afetividade: um breve histórico}

No início da década de 2000, quando o acesso à internet ainda era discado na maioria das casas, e os smartphones ainda eram ficção científica, muito se falava que a web proporcionaria a formação de uma aldeia global. Pierre Levy (1998), dentre outros teóricos, apontavam para a formação de uma inteligência coletiva, ou seja, uma rede de informações fragmentadas que quando combinadas poderiam ajudar a humanidade a realizar grandes feitos. De fato, muita informação é acumulada e armazenada proporcionando avanços científicos para muitas pessoas e instituições. No entanto, nos últimos anos, percebe-se o crescimento de um outro tipo de uso para as tecnologias. Atualmente, o maior volume de dados compartilhados se dá através da exposição pessoal e interações em relacionamentos de amizade, familiares ou amorosos.

Ou seja, o uso que as pessoas dão aos dispositivos digitais e à própria rede relaciona-se muito mais com afetividade do que construção de saber. Sherry Turkle (2011), no seu livro "Alone Together: why we expect more from technology and less from each other", comenta que as pessoas já consideram que a realidade a qual têm acesso nos smartphones se torna uma extensão da realidade física e presencial à qual se encontram. Trazendo aos indivíduos uma sensação de estarem a poucos cliques de pessoas que podem Ihe fazer companhia e proporcionar conforto social. A autora aponta que é como se as pessoas pudessem puxar um amigo de dentro da bolsa a qualquer momento. Além do mais, atualmente percebe-se que essa relação com a tecnologia penetra em várias esferas da sociedade, atingindo diferentes gerações, desde milleniums até baby boomers.

Ainda na década de 1990 já era possível observar a motivação de uso de redes de computadores para colocar as pessoas em contato. 0 próprio correio eletrônico já era uma realidade antes mesmo da criação da world wide web, já que os primeiros protocolos foram criados na década de 1970 dentro da ARPANET. O ICQ ${ }^{4}$, criado em 1996 foi um programa pioneiro na internet de troca de mensagens instantâneas inaugurando o espaço eletrônico para comunicações afetivas. 0 software foi uma das primeiras formas para as pessoas se colocarem em contato e criarem redes sociais online, fosse para reforçar contatos com pessoas com quem conviviam presencialmente, ou ampliar sua rede acessando indivíduos de qualquer lugar no mundo.

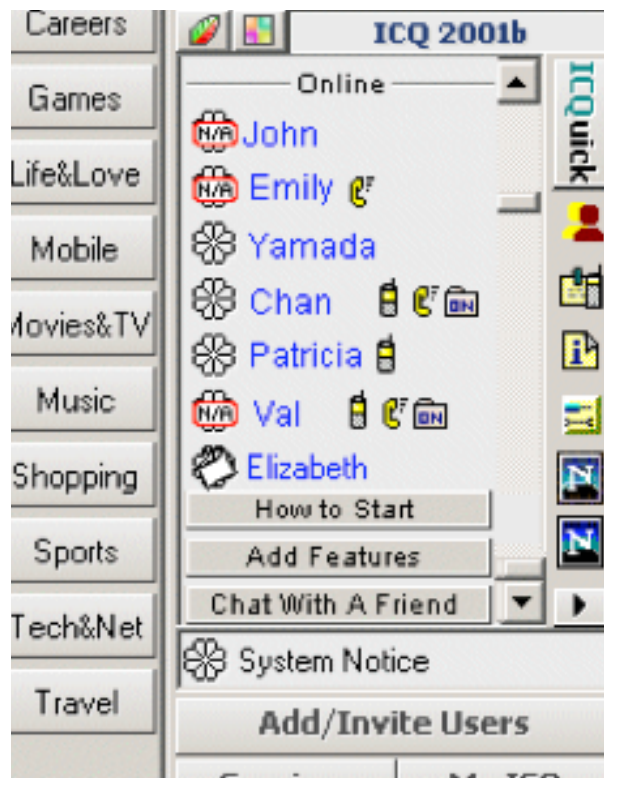

Figura 1 - Software ICQ de comunicação instantânea.

Esta motivação afetiva, portanto, aparece desde os primórdios da internet, funcionando como uma extensão da própria necessidade de se colocar em ligação com grupos do ser humano. De acordo com Recuero (2012), as pessoas se apropriam dos espaços online para conversação, adaptando-0 de acordo com as possibilidades para emular conversas que ocorreriam no âmbito presencial. Porém, nestes espaços são criados rituais diferenciados daqueles já comuns na comunicação oral, com convenções simbólicas próprias que são negociadas através das trocas pelos próprios participantes.

Além disso, é possível afirmar que estes rituais também se modifiquem dentro dos próprios espaços virtuais, variando de acordo com a ferramenta que está sendo usada, ou apenas por surgirem novos modismos dentro de uma mesma ferramenta. No Facebook, por exemplo, inicialmente a forma de trocar conteúdo era através do feed de notícias, em que as pessoas postavam fotos ou textos fixos que podiam ser visualizados por seus amigos que entrassem na plataforma e acionassem a rolagem do feed. Mais tarde, inspirando-se no aplicativo Snap Chat, a plataforma criou a possibilidade dos stories, funcionalidade em que as pessoas podem postar vídeos ou imagens que ficarão

\footnotetext{
2 Fonte - https://www1.folha.uol.com.br/tec/2018/07/facebook-chega-a-127-milhoes-de-usuarios-mensais-no-brasil.shtml

3 Fonte - https://www.statista.com/statistics/578364/countries-with-most-instagram-users/

${ }^{4}$ Fonte - http://icq-planet.com/the-history-of-icq/
} 
disponíveis para visualização por um tempo determinado, sendo excluídas ao término deste. Isso demonstra que as trocas e rituais de conversação online estão se tornando cada vez mais efêmeros, com uma potencialidade de ressignificação bastante acelerada.

É preciso ter o cuidado e não simplesmente afirmar que tudo isso é reflexo das tecnologias criadas. A própria tecnologia já é uma consequência das necessidades e pesquisas que surgem em seu tempo. De forma que se trata de um processo de retroalimentação em que as trocas sociais alteram as tecnologias ou inspiram a criação de novas ferramentas. E, em contrapartida, as tecnologias potencializam os eventos sociais para além da perspectiva presencial.

\section{Autoimagem e grupos de interesses}

Ao passo que os indivíduos passaram a andar com um celular no bolso, os mesmos têm disponível uma ferramenta de geração de conteúdo poderosa que não era nem pensada até algumas décadas atrás. É possivel gerar narrativas pessoais, traduzi-la em diversas linguagens e compartilhar para 0 mundo em questão de segundos. Isso se torna um hábito à medida que as pessoas obtêm retorno positivo e mais trocas sociais em suas redes. Além de que esta prática ao longo do tempo pode formar uma reputação favorável para quem a constrói.

As pessoas querem estar presentes nos acontecimentos mesmo de longe. Saber em Porto Alegre o que seus amigos estão fazendo em Paris ou Melbourne. Mas também querem reconhecimento e feedback positivo dos seus contatos naquilo que postam, sejam textos, fotos ou vídeos. Com essa dinâmica surgem sentimentos de realização e frustração quando o objetivo não é alcançado. Assim, mais do que mera conversação, os rituais formados pelas trocas em redes sociais permeiam o afetivo através da necessidade de autoafirmação e aprovação daqueles que participam dos mesmos espaços. E com as possibilidades de divulgação em grande escala, muitas pessoas se colocam em ligação com um número de contatos ou seguidores cada vez mais alto, composto de desconhecidos em sua maioria.
Sobre a formação da sociedade em rede, Castells (1999) cria o conceito de "matéria-prima"social, referindo-se a artefatos culturais, costumes e relações sociais. De acordo com o autor, as redes se formam através do processamento dessa matéria-prima pelos atores sociais coletivos. Estes absorvem as referências que têm a sua volta e as influências externas, realizando escolhas baseadas em direcionamentos de vida, de gostos e de necessidades, bem como de conveniências. A partir dessa colocação é possível traçar um paralelo com a necessidade de autoafirmação que as pessoas desenvolvem com suas postagens em redes sociais online.

Também para Sibillia (2008) os espaços de trocas sociais na internet proporcionam a possibilidade de que as pessoas compartilhem suas histórias criando uma nova realidade em que toda narrativa merece ser contada. Segundo a autora, existe uma tendência em transformar histórias pessoais em formatos adaptados a códigos audiovisuais já conhecidos por mídias de entretenimentos, como filmes ou séries. Estes códigos influenciam os sujeitos os levando a interpretarem suas vidas de acordo com estas linguagens. Porém, mais recentemente é possível dizer que formatos e linguagens gerados pelos próprios indivíduos através do uso das redes sociais online, acabam por influenciar as mídias de entretenimento, criando um processo em que um influencia 0 outro em momentos diferentes.

Os influenciadores de redes sociais, por exemplo, tornam-se um grupo cada vez mais conhecido na sociedade como um todo. Em sua maioria são criadores de conteúdos, principalmente para as plataformas do Youtube ou Instagram, muitos deles tendo também blogs pessoais hospedados em domínio próprio. Os conteúdos gerados por estes sujeitos possuem um planejamento, muitas vezes até um roteiro quando são vídeos, mas mesmo se tratando de fotos, há uma construção para garantir uma qualidade estética.

Algumas influenciadoras de moda e estilo de vida, como Thássia Naves ${ }^{5}$ e Gabriela Pugliesi 6 , postam fotos produzidas por fotógrafos profissionais, feitas com preparação do vestuário, maquiagem e cabelo. 0 resultado disso são imagens que dificilmente se assemelham com um cotidiano de uma pessoa normal, produzindo uma narrativa que tenta simular uma situação real quando na verdade não é o caso.

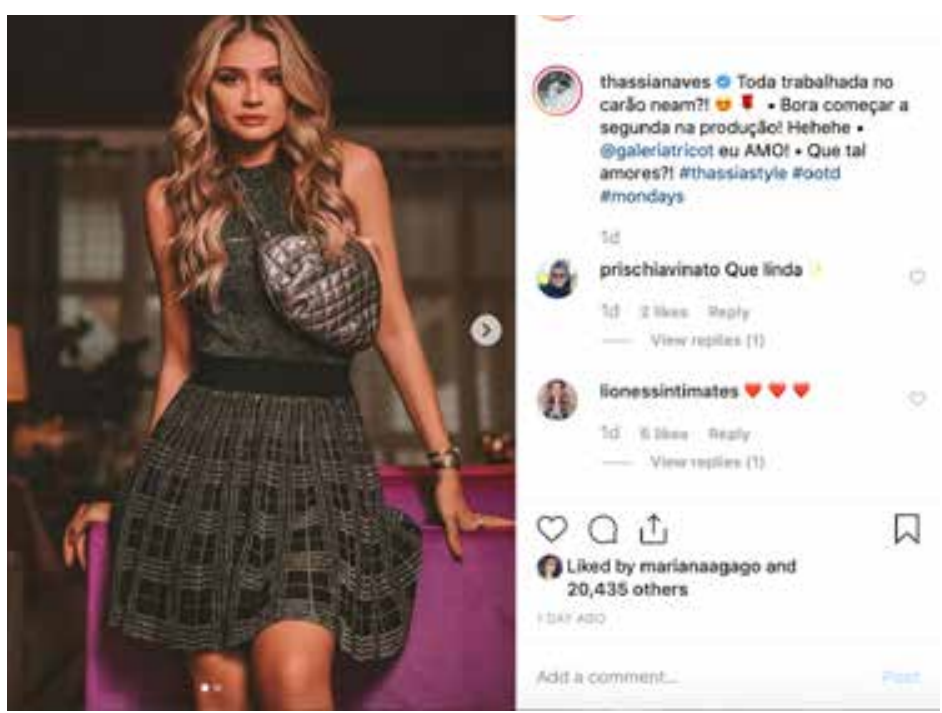

Figura 2 - publicação na conta do instagram de Thassia Naves de 29/07/2019

\footnotetext{
5 http://instagram.com/thassianaves

${ }^{6}$ http://instagram.com/gabrielapugliesi
} 
Estes influenciadores e influenciadoras tornaram-se veículos bastante usados para anúncios publicitários. Para muitos deles a maioria das postagens presentes em seus perfis são os chamados de "publi posts", em que um ou mais produtos são promovidos sob contrato de marcas que possam interessar seu segmento de público. Assim, contas em redes sociais online que a princípio deveriam retratar o cotidiano de uma pessoa, em muitos casos se assemelham mais a um catálogo de moda, com produção profissional e teor publicitário.

Estas práticas, apesar de não serem ilegais ou mesmo antiéticas com relação à política das plataformas, acarretam alguns efeitos negativos na organização social. As principais críticas são em função da relação que pessoas têm com essas redes sociais. Principalmente por se sentirem frustradas por não terem uma vida parecida com a do influenciador, ou por não possuírem tantas curtidas em suas fotos quanto eles. Inclusive, a partir do segundo semestre de 2019 a plataforma tomou a iniciativa de testar a ocultação das curtidas alegando estarem preocupados com a saúde mental de seus usuários.

0 sistema de curtidas e outras formas de engajamento em redes sociais, como comentários e mensagens, auxilia estas plataformas a criarem grupos de interesses demográficos devido a a acúmulo de dados. Isso funciona conforme a descrição de Maffesoli (2005) sobre as identificações que pessoas têm com determinados grupos sociais que possuem interesses em comum. As pessoas se colocam em estado de religação a partir desses interesses em comunidades que dividem códigos de valores. Os indivíduos podem alternar participações em diferentes grupos sociais de acordo com seus interesses.

Assim, vão se criando novos movimentos, ou alguns movimentos que já existiam passam a ganhar mais visibilidade. A partir do momento em que pessoas se identificam com estes movimentos, seguem perfis relacionados a eles, e passam a absorver para seu repertório pessoal gírias, padrões de comportamento e linguagens estéticas. E da mesma forma, estas manifestações podem trazer consequências negativas e positivas, atingir extremos, se desmembrarem, ou mesmo se transformarem em outros movimentos.

Éo caso do movimento LGBTQI+, que recentemente teve a sigla revisada, sendo até pouco tempo identificado como LGBT. Apesar da parcela da sociedade ainda receber muito discurso de ódio, o movimento ganha força com influenciadores que apoiam a causa e auxiliam trazendo maior visibilidade, além de divulgar ações conjuntas ou eventos físicos. É o caso de youtubers como Lorelay Fox (Danilo Dabague) ${ }^{7}$ e Rita Von Hunty (Guilherme Pereira) 8 , personagens drag queens que utilizam seus canais para apoiar a causa e dar uma nova imagem a este segmento da sociedade.

Outro movimento que ganha força é o Body Positive criado nos Estados Unidos em 1996 por Sobczak and Elizabeth Scott ${ }^{9}$ e que tem crescido no Brasil nos últimos anos. 0 movimento espalha ideais de autoaceitação, autoestima e ressignificação de padrões de beleza, além de um melhor relacionamento que as pessoas têm com sua própria imagem. Os principais influenciadores deste movimento no Brasil são Alexandra Gurgel do canal Alexandrismos ${ }^{10}$ e Bernardo Boechat ${ }^{11}$ do canal Bernardo Fala. Eles criam conteúdo voltado para formação de autoestima e de combate ao bulling e cyberbulling, além de promoverem eventos para divulgarem a proposta.

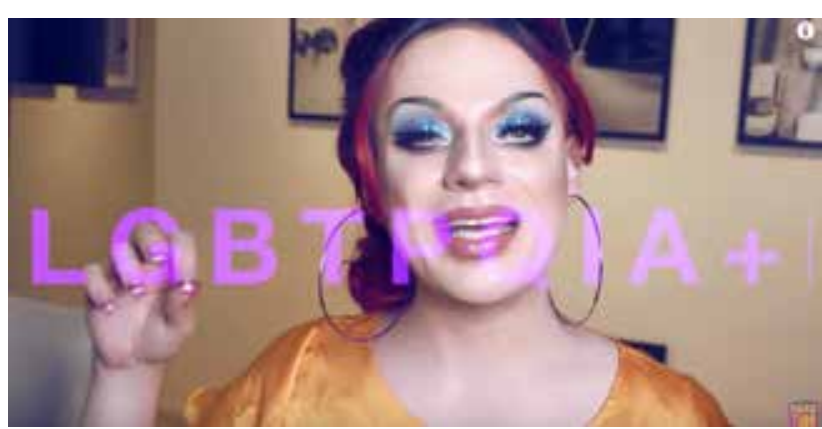

Figura 3 - Danilo Dabague em sua personagem drag queen Lorelay Fox, no canal Para Tudo do Youtube.

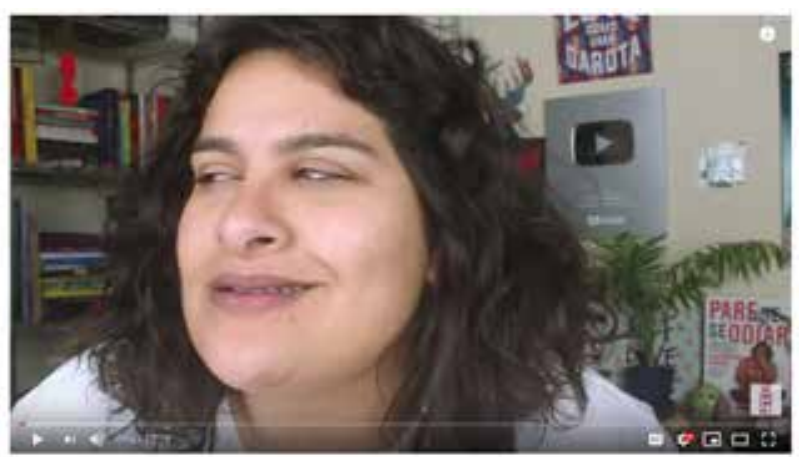

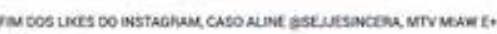
$\cos \sin \operatorname{mon}$

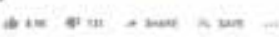

Figura 4 - vídeo do canal Alexandrismos de Alexandra Gurgel no Youtube.

Assim, as relações que as pessoas criam com as redes sociais online são um reflexo das próprias necessidades sociais que ganham novas proporções e maior visibilidade. Elas podem acarretar aspectos negativos como frustração e depressão, mas também podem gerar novos significados e novos padrões de comportamento.

\section{Aplicativos de namoro: padrões de comportamento e cultura do "swipe"}

Desde que a internet passou a ser usada para troca de mensagens pessoais, as pessoas passaram a aproveitar o meio também para paqueras e encontros amorosos, seja com pessoas próximas ou distantes. Inicialmente ferramentas não originalmente criadas para isso foram apropriadas e ressignificadas, como o próprio ICQ já citado, o MSN da Microsoft e o Bate-papo da UOL.

Mas, não demorou para que al gumas empresas lançassem redes sociais focadas em relacionamentos como Ok Cupid, E-harmony e Badoo. Mas a partir da década de 2010, com o aumento do uso dos aparelhos de telefone celulares, criou-se uma nova forma de paquerar na internet com o surgimento

\footnotetext{
7 https://www.youtube.com/channel/UC-NW3bCGpuJm6fz-9DyXMjg

8 https://www.youtube.com/channel/UCZdJE8KpuFm6NRafHTEIC-g

9 Fonte-https://www.thebodypositive.org/about

${ }_{10}$ https://www.youtube.com/channel/UC2LQ5jMieMZjb5k5Gprp2JQ

$11 \mathrm{https}: / /$ www.youtube.com/channel/UCv1RFVLBWD-cqUwocOF2qKQ
} 
do Tinder em 2012. Este aplicativo popularizou a cultura do "swipe", em que 0 usuário visualiza fotos de pessoas para paquerar e desliza para a esquerda caso não esteja interessado, e para a direita caso esteja interessado. Posteriormente outros aplicativos surgiram com a mesma proposta, como o Happn e mais recentemente o Date associado à plataforma do Facebook.

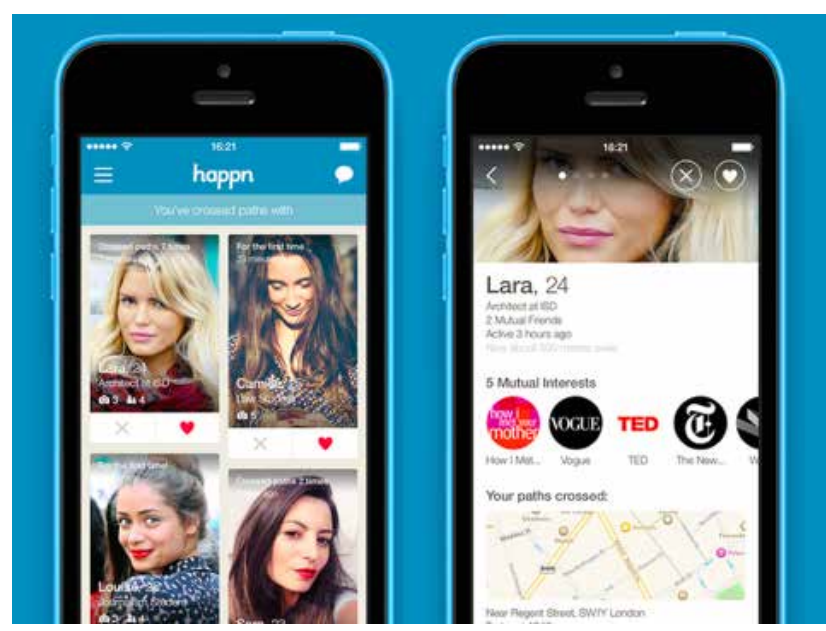

Figura 5 - Interface do aplicativo de relacionamentos Happn.

A cultura do "swipe" cresceu e ganhou força nas comunidades de solteiros de todas as classes sociais e diferentes idades. Este fenômeno demonstra 0 aumento da efemeridade das relações humanas, realidade que cresce com as novas demandas de velocidade em todos os âmbitos da sociedade, como em situações de economia e trabalho. Acabando por incorporar os contextos de relações mais íntimas. Não é necessariamente negativo ou positivo, apenas uma nova forma de se relacionar que se encaixa melhor no cotidiano das pessoas que acabam por contar com as tecnologias para quase todas as suas atividades.

\section{Conclusão}

Reforça-se, portanto, a ideia de que não é a simples existência da tecnologia que gera estes comportamentos como se surgissem do nada. A própria sociedade e suas demandas geram novas formas de relações sociais que passam a ser potencializadas pela tecnologia. Ganham uma escala global e mais visibilidade.

Assim, as tecnologias não devem ser vistas como nocivas ou prejudiciais, muito menos serem proibidas ou moderadas por instituições governamentais. Deve-se sim, educar as pessoas e difundir informações para que cada um tenha sua capacidade crítica a fim de decidir qual uso pode melhor se encaixar às suas expectativas e necessidades.

\section{Referências}

Castells, M. (1999). O Poder da Identidade. São Paulo: Paz e Terra.

Levy, P. (1998). A Inteligência Coletiva: por uma antropologia do ciberespaço. São Paulo: Editora Loyola.

Maffesoli, M. (2005). O Mistério da Conjunção. Porto Alegre: Sulina.

Recuero, R. (2012). A Conversação em Rede: comunicação mediada pelo computador e redes sociais na internet. Porto Alegre: Sulina.

Sibillia, P. (2008). OShow do Eu: a intimidade como espetáculo. Rio de Janeiro: Nova Fronteira.

Turkle, S. (2011). Alone Together: why we expect more from technology and less from each other. Cambridge: MIT Press. 